\title{
A controlled monitoring study of simulated clandestine graves using 3D ground penetrating radar
}

\author{
M. van Schoor ${ }^{1}$, W.C. Nienaber ${ }^{2}$ and A. Marais-Werner ${ }^{2}$ \\ ${ }^{1}$ Council for Scientific and Industrial Research (CSIR), Pretoria, South Africa \\ ${ }^{2}$ University of Pretoria, South Africa \\ E-mail: mvschoor@csir.co.za
}

\begin{abstract}
A controlled 3D GPR monitoring study over simulated clandestine graves was conducted near Pretoria, South Africa, in which the detectability of graves as a function of post-burial interval was assessed, as this is of particular interest to local forensic investigators. It was demonstrated that the site-specific environmental parameter (a clay-rich loamy soil with poor drainage) and heavy seasonal rainfall (as confirmed by GPR-derived soil moisture estimates) drastically compromised the long-term grave detectability, especially when adopting a 3D depth slice analyses approach. It is also seen that the disturbed burial zone is the major contributor to the total grave anomaly rather than the buried body due to the combination of environmental parameters and the absence of buried artefacts. This paper also advocates the combined use of different data representations (2D and 3D) to increase the likelihood of detecting subtle grave anomalies.
\end{abstract}

\section{INTRODUCTION}

Ground penetrating radar (GPR) is a widely used and versatile near-surface geophysical method that has been applied to a diverse range of earth science problems; for example, utility detection, concrete and infrastructure studies, mining and hydrogeophysics. Although the most common fields of application are still utility detection and concrete and infrastructure studies (Pers. Comm., Greg Johnston, Sensors \& Software Inc., 22 September 2016), the use of GPR is on the rise in the field of forensic geoscience (Schultz, 2012; Pringle et al., 2012).

The popularity of GPR is due to its capability to survey large areas in relatively short times and at a relatively high (cm-scale) resolution. Barone et al. (2016) also highlighted the onsite real-time processing capability of modern GPRs as a further key benefit. Most commercially available GPR systems employ a constant-offset transmitter and receiver antennae configuration that can be mounted on a push-cart. A 3D or grid survey 
approach is commonly used to cover large areas for the purpose of depth slice extraction and 3D data visualisation. 3D GPR surveys typically involve a grid of equidistant parallel profiles acquired in two perpendicular directions to optimise spatial resolution. Data acquisition is usually conducted at a single operating frequency in the range $100-1000 \mathrm{MHz}$ and the resulting depth of investigation is typically limited to the first few meters of the near-surface. In GPR there is a trade-off between range and resolution: increasing the operating frequency implies a higher resolution, but at the cost of a decreasing range associated with the corresponding increase in attenuation; similarly, a lower operating frequency will enable a greater depth of investigation, but at a reduced mapping accuracy.

GPR studies that relate to grave detection can be classified as either of a heritage or a forensic nature. In heritage-related studies the typical survey aim is to identify unmarked cemetery graves; for example, Fiedler $e t$ al. (2009), Hansen et al. (2014) and Barone et al. (2016). Forensic studies typically involve the somewhat more challenging task of searching for clandestine burials; for example: Pringle et al. (2008) advocated the use of a multi-technique approach to identify possible clandestine burials in an urban environment and using GPR as a follow-up tool for obtaining better resolution on selected anomalies; however, the challenges associated with detecting subtle clandestine burial anomalies using GPR in the noisy and heterogeneous ground conditions of urban environments were highlighted. Schultz (2008) studied the monitoring of pig cadaver burials in sandy soils, and emphasised the difficulty of detecting anomalies after a few months because the disturbed zone does not present as strong a GPR contrast as soils with distinct horizons or higher clay content might. Doolittle and Bellantoni (2010) focused on the site-specific applicability of GPR in a soil type, which is generally considered as favourable for GPR due to its low clay content; however, the lack of well-developed soil horizons and the associated relatively low contrast of the disturbed (burial) zone, as well as the presence of undesirable scattering bodies such as tree roots, rock fragments, animal burrows and modern cultural debris are described as challenges. Schultz and Martin (2012) also reflected on the previously mentioned problem of detecting clandestine burial in sandy environments, particularly when the body is buried without any artefacts or coverings that may enhance the grave anomaly to some extent. In fact, the difficulty in detecting clandestine burials is often attributed to the absence of a coffin, container or other artefacts (Pringle et al., 2008; Doolittle and Bellantoni, 2010; Novo et al., 2011). The covert nature of such burials and the fact that no record exists imply a greater degree of uncertainty in terms of anticipated location, orientation, age and depth of burial. Another variable that may adversely affect the GPR detectability of clandestine burials is the soil moisture 
content, due to the associated increase in bulk soil conductivity (implying a decrease in GPR range). However, in some cases (depending on the combination of soil type and state of decomposition) an increase in soil moisture may actually contribute to an enhancement of grave anomalies (Schultz and Martin, 2012; Molina et $a l ., 2015)$. It is clearly evident that the detection of clandestine burials using GPR is a challenging problem that is highly dependent on a range of site-specific, cultural and environmental variables and since forensic geophysics is also a relatively new application field, there is a definite need for a variety of benchmarking studies to advance the knowledge in this field.

In South Africa, the applicability of GPR to forensic cases has in recent years attracted the attention of criminal investigators, with the South African Police Services (SAPS) acquiring several GPR units. However, the frequency of use for clandestine grave searches is low due to insufficient training and poor technical support of the investigating officers; for example, during the period January 2015 to July 2016, GPR was only used in three out of 32 clandestine grave search cases (Pers. Comm. Colonel L Rossouw, SAPS VIC, 25 July 2016; Major W Ngoma, SAPS Gauteng Crime Scene Management Unit, 26 July 2016). There clearly exists a need to empower local crime scene investigators in the use of geophysical tools such as GPR and case studies such the one described in this paper can make a positive contribution in this regard.

Between September 2014 and May 2015, researchers from the Forensic Anthropology Research Centre of the University of Pretoria (UP) conducted a taphonomic study at a controlled test site. The aim of this study was to investigate the rate and pattern of decomposition associated with shallow, clandestine burials in the local soil and environmental conditions. Pig cadavers were used as proxy for human bodies as is commonly done in such studies (e.g., Schultz, 2008; Molina et al., 2015). Although geophysical monitoring did not originally form part of the taphonomic research plan, it was decided to run a time-lapse GPR monitoring experiment in parallel with the taphonomic study and as part of a research collaboration between UP and the Council for Scientific and Industrial Research (CSIR).

Four 3D GPR surveys were conducted between November 2014 and March 2015 and preliminary results and findings were reported on in Van Schoor et al. (2015). Two additional 3D GPR scans were conducted between April 2015 and August 2015 and are reported on for the first time in this paper. A more quantitative assessment 
of local soil moisture conditions was also added and these additional data sets helped to support and expand on the previously reported findings.

In the context of earlier forensic geophysics studies relating to the application of GPR for clandestine grave detection, this study involves a unique combination of survey parameters and methodologies, not previously described. The survey parameters include shallow clandestine burials with no body coverings or other artefacts, a clay-rich loamy soil characterised by poor drainage and a dominant environmental variable in the form of a seasonal rainfall spike. In terms of methodologies, the relationship between soil moisture and 3D GPR performance is investigated by considering both rainfall data and GPR-derived soil moisture content estimates. This controlled monitoring study also represents the first of its kind in South Africa and possibly on the African continent.

\section{TEST SITE AND SURVEY APPROACH}

The Forensic Anthropology Body Farm (FABF) of the University of Pretoria is located on an experimental farm (Miertjie le Roux), $30 \mathrm{~km}$ east of Pretoria. For the purpose of the taphonomic study, provision was made for a total of 40 simulated clandestine graves; the layout was a regular grid of ten rows of four graves each. The dimensions of individual graves were approximately $2.2 \mathrm{~m} \mathrm{x} 1.2 \mathrm{~m}$ x $0.75 \mathrm{~m}$, with a spacing of $2.5 \mathrm{~m}$ between graves; the total effective area of the final grid was approximately $42 \mathrm{~m} \times 17 \mathrm{~m}$ (Figure 1)

The FABF site is located in a warm and temperate climatic region of South Africa in which the summer (DecFeb) receives a much higher rainfall than the winter (Jun-Aug). The GPR study described here therefore commenced in late spring, just after the onset of the rainy season. The soil cover at the FABF site can be classified as a Hutton form soil (Pers. Comm., Garry Paterson, Agricultural Research Council, Institute for Soil, Climate and Water, 20 December 2016). This red loamy soil, which has relatively high clay content, is characterised by poor drainage. The poor drainage, coupled with the elevated electrical conductivity often associated with this type of clay-rich soil, is expected to impact negatively on the performance of the GPR method. 


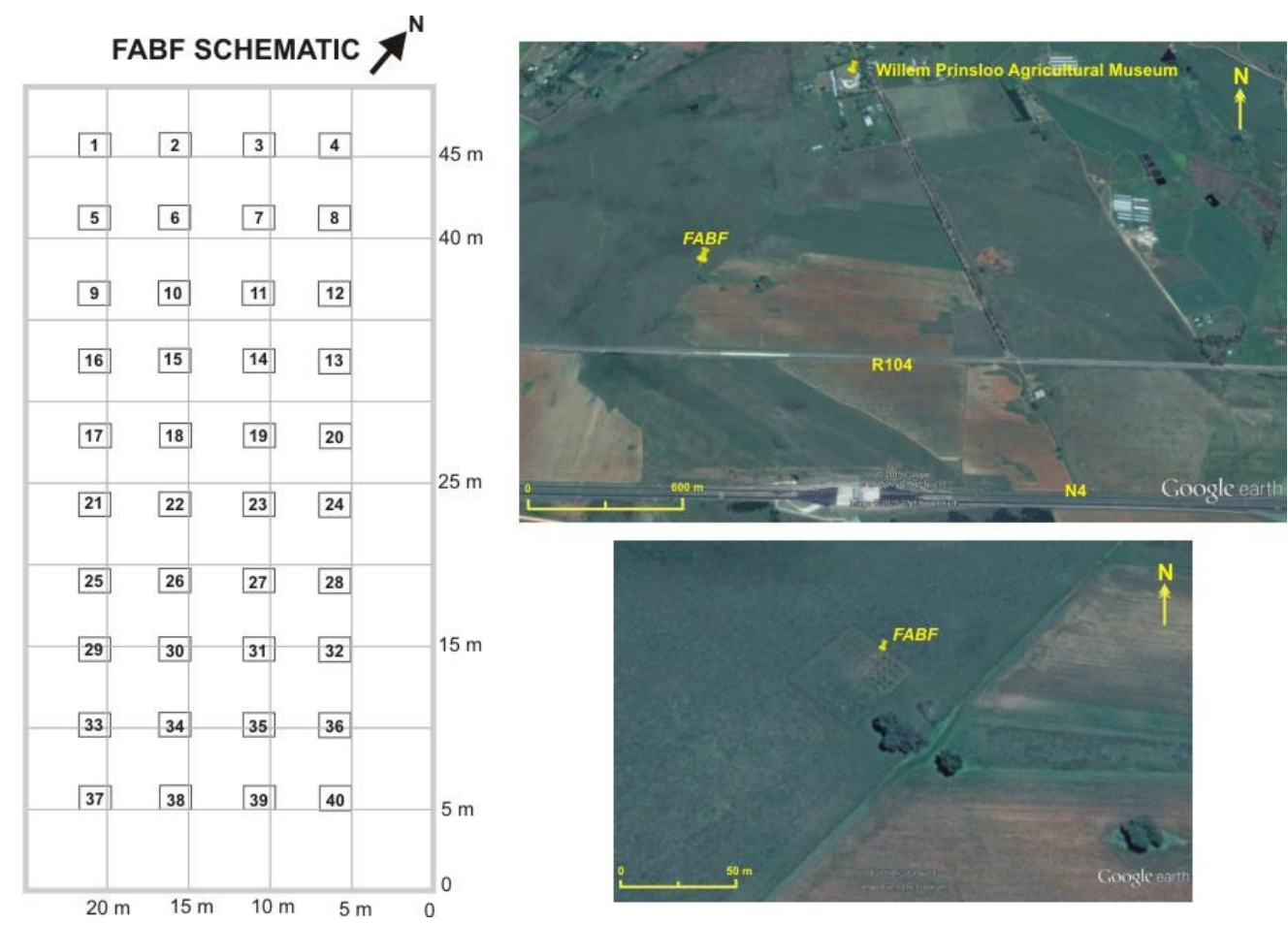

FIGURE 1: 3D GPR surveys conducted at the FABF site 
Carcasses of pigs that had died of natural causes were buried as they became available from nearby piggeries throughout the study period. The taphonomic study required the excavation (removal of carcass and backfilling of grave) at prescribed intervals (7 days, 2 weeks, 1 month, 3 months and 6 months). The excavation and subsequent backfilling of individual graves occurred on the same day in all cases. 3D GPR surveys were conducted on a total of six occasions between November 2014 and August 2015. On each of these occasions, the 3D GPR grid covered all the existing simulated graves (both intact and excavated). This approach ensured that GPR data were acquired for a variety of scenarios, ranging from relatively fresh burials (3 days) to older than 180 days, as listed in Table 1. Note that the decisions to excavate specific graves at specific times were not driven by the GPR study, but rather by the parallel taphonomic study. The GPR study simply piggy-backed on the latter study.

In forensic GPR investigations, an operating frequency between approximately $200 \mathrm{MHz}$ and $500 \mathrm{MHz}$ is typically used; Even though the highest possible resolution is often desired in forensic investigations, local soil conditions and the previously described range-resolution trade-off sometimes make that a lower frequency option is a more appropriate choice. In this study an operating frequency of $250 \mathrm{MHz}$ was selected as it provided a good balance between range, resolution, and survey productivity. Consequently, a Rock Noggin GPR system (by Sensors \& Software, Inc.), with a Smart Cart and $250 \mathrm{MHz}$ shielded antenna, was employed.

For all six 3D GPR surveys, data were acquired in two perpendicular directions to optimise lateral resolution. The survey grid was defined so that the X-lines would be parallel to the short grave axes and the Y-lines parallel to the long grave axes (Figure 1). A profile spacing of $25 \mathrm{~cm}$ was used, while the effective inline sampling interval (step size) was $0.05 \mathrm{~m}$. The depth range was set to approximately $2 \mathrm{~m}$ and the effective time sampling interval equated to approximately $0.015 \mathrm{~m}$, based on an assumed bulk ground velocity of $0.1 \mathrm{~m} / \mathrm{ns}$. In-line positioning accuracy was achieved by using the Smart Cart odometer system. 


\begin{tabular}{|c|c|c|c|}
\hline $\begin{array}{c}\text { Survey } \\
\text { number }\end{array}$ & Date of survey & Graves included & Effective survey area \\
\hline 1 & 3 November 2014 & $1-20$ & $21 \mathrm{~m} \times 17 \mathrm{~m}$ \\
\hline 2 & 3 December 2014 & $1-24$ & $25 \mathrm{~m} \times 17 \mathrm{~m}$ \\
\hline 3 & 9 January 2015 & $1-24$ & $25.5 \mathrm{~m} \times 17 \mathrm{~m}$ \\
\hline 4 & 31 March 2015 & $1-32$ & $35 \mathrm{~m} \times 17 \mathrm{~m}$ \\
\hline 5 & 16 April 2015 & $1-32$ & $43.25 \mathrm{~m} \times 17.5 \mathrm{~m}$ \\
\hline 6 & 31 August 2015 & $1-40$ & $42 \mathrm{~m} \times 17 \mathrm{~m}$ \\
\hline
\end{tabular}

TABLE 1: 3D GPR surveys conducted at the FABF site 


\section{DATA PROCESSING AND VISUALISATION}

For each of the six GPR surveys the same approach to processing and analysis was followed: Individual 2D profiles were first processed using the REFLEXW software (by Sandmeier Scientific Software). Standard processing steps included:

(1) A time-zero correction;

(2) mean subtraction (dewow) to eliminate unwanted low-frequency components from the data;

(3) automatic gain control (AGC) to amplify low-amplitude ranges; and

(4) background removal to suppress horizontally coherent energy and to emphasise anomalies that vary laterally such as diffractions.

An example of a processed 2D radargram - and how it changes over time - is shown in Figure 2. The selected GPR profile is X024 that traversed grave numbers 19, 14, 11, 7 and 3 during the first 3D survey in November 2014. In the subsequent surveys, profile X024 also traversed graves 23 (from December 2014 onwards), graves 27 and 31 (from March 2015 onwards) and graves 35 and 39 (from April 2015 onwards).

In addition to the $2 \mathrm{D}$ analyses described above the respective $3 \mathrm{D}$ data sets were processed for the purpose of generating depth slices. To achieve this Sensors \& Software's GFP_Edit software was employed for the georeferencing of grid profiles and to produce the 3D input file for Sensors \& Software's depth slice module, Ekko_Mapper. The Ekko_Mapper software can either operate on a data set that were previously processed in other software (such as REFLEXW) or it can be set up to apply a standard sequence of processing steps to all the data prior to slicing through the volume of data. A typical processing sequence for depth slice generation includes amplitude equalisation gain, velocity-based migration, envelope filtering and background subtraction. The migration filter is designed to contract diffractions and to move steeply dipping reflectors to their true spatial positions, while the envelope filter aims to suppress the oscillatory nature of radar responses and provides a simplified visualisation of spatial resolution (Annan, 1999). 
GRAVE NUMBER

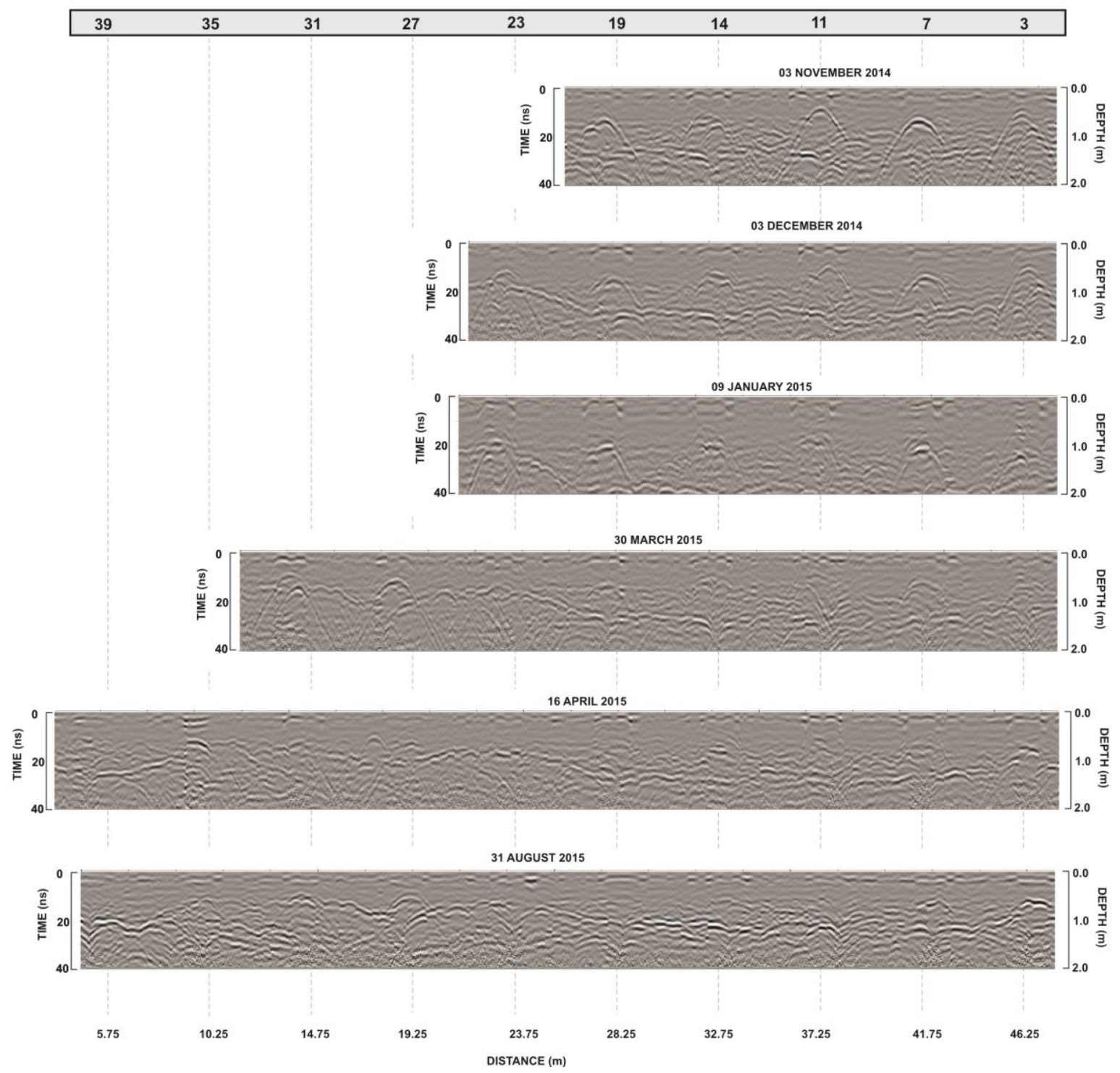

FIGURE 2: Time-lapse GPR results for a selected 2D profile with a SE-NW orientation that crosses grave numbers $19,14,11,7$ and 3. 
Selected 3D GPR results are shown in Figures 3-8; in each case the depth slice was selected that best revealed the presence of the simulated graves. For each of the six 3D surveys, a grave status grid plot is included, which provide information regarding the elapsed time since original burial as well as time elapsed since the most recent disturbance (excavation or scavenging). The key included with Figure 3 details the notation used in these plots.

\section{DISCUSSION OF RESULTS}

In previous similar studies it was pointed out that both the buried body as well as the disturbed burial zone contributed to an observed clandestine grave anomaly (Schultz and Martin, 2012; Salsarola et al., 2015). The magnitude of these responses is however expected to become less pronounced over time due to decomposition of the body, settling or compaction of soil and rainfall drainage. The impact of these variables at the FABF site becomes evident when monitoring and comparing the changes in GPR responses for the respective surveys:

\section{November 2014}

For post-mortem intervals of 34 days and less, the grave anomalies are clearly discernible as hyperbolic reflections on the non-migrated 2D radargrams (Figure 2) and also on the corresponding depth slice image (Figure 3). There appears to be no significant differences between the responses of the slightly older graves $(3,7$ and 11) and the more recent burials (19 and 14) in Figure 2 and the same observation is also valid when comparing the other grave anomalies that are present in the 3D depth slice in Figure 3 . It should however be pointed out that the post-mortem ages of all these graves were between 25 and 34 days and comparisons involving burials that are only a few days old were not possible.

The responses of graves 2 and 5 provide some interesting insights: These two graves were scavenged by jackals within a few days before the 03 November survey. These graves were then backfilled a day before the GPR survey with hardly any remains in the case of grave number 2, while the carcass of grave number 5 was still largely intact. Selected radargrams that include the corresponding responses are shown in Figure 4 and it appears that the scavenged grave responses are only marginally different when compared to the other undisturbed graves with the reflection hyperbola tails of the former being less pronounced. However, purely in terms of detectability, there is no major discernible differences in the 2D and 3D responses between, for 

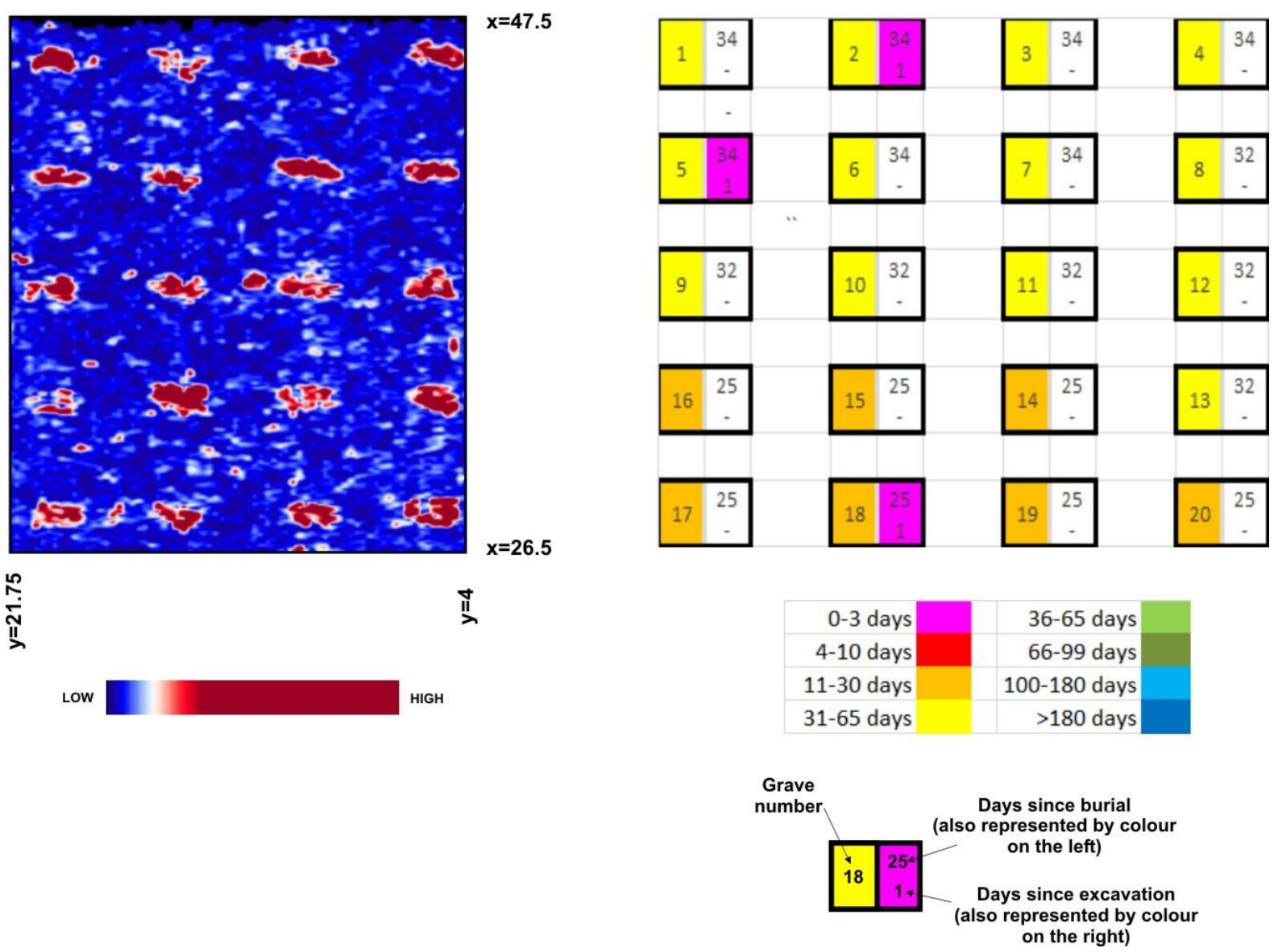

FIGURE 3: Depth slice image $(0.6-0.7 \mathrm{~m})$ for the 03 November 2014 survey; the schematic legend shows the period since initial burial (represented by colour of left half of grave blocks) and excavation (colour of right half of blocks) for corresponding graves. 

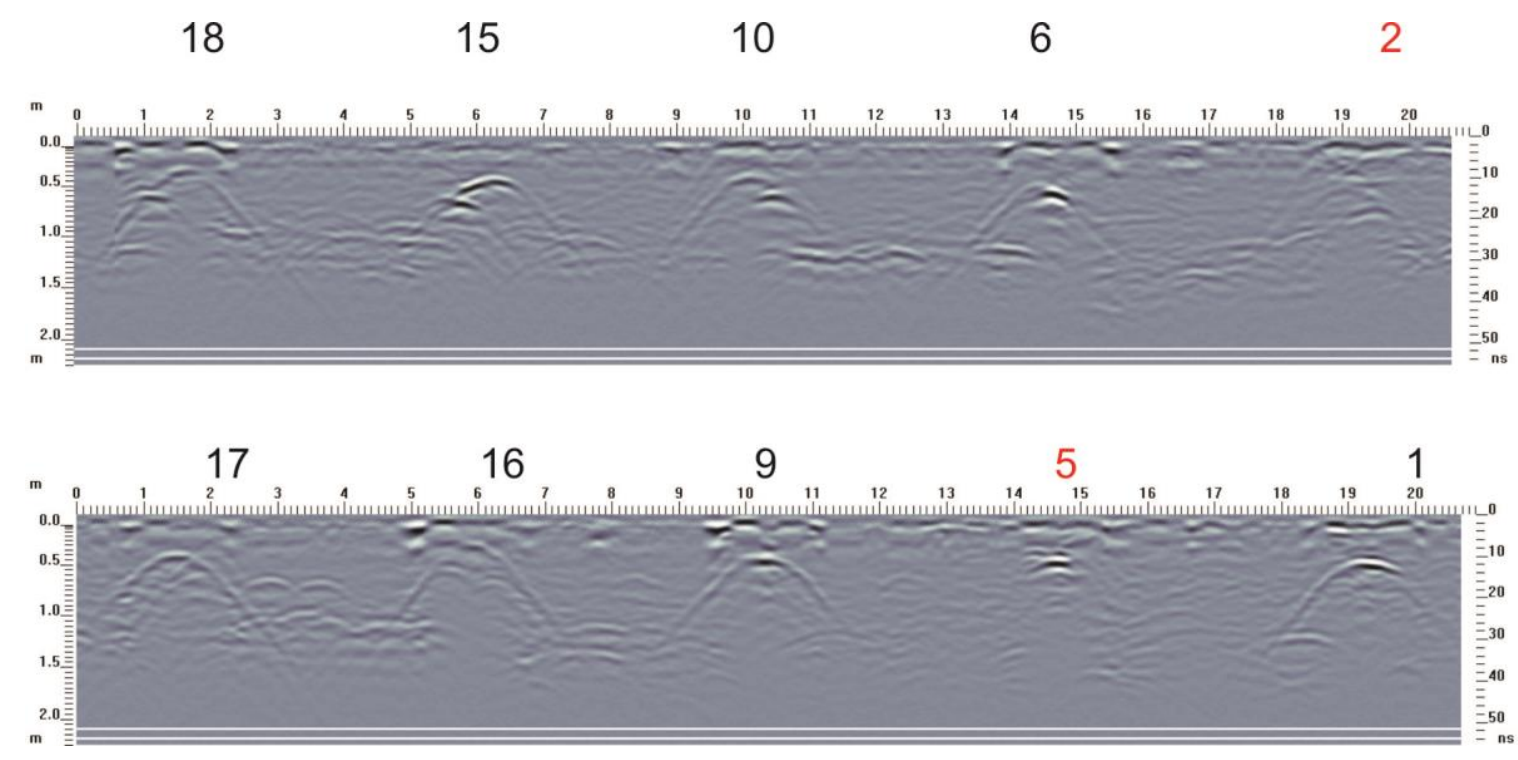

FIGURE 4: 2D profiles from the 03 November 2014 survey that transects the two scavenged and backfilled graves, numbers 2 and 5 . 
example, the scavenged grave number 2 (without a body) and other undisturbed graves; this suggests that the disturbed burial zone is probably the major contributor to the total grave anomaly in this particular environment. However, this inference needs to be assessed for graves that are only a few days old because in the early stages of decomposition, when the thorax cavity is still intact and hasn't collapsed, the associated cavity response may be relatively significant. A previous study by Schultz (2008) suggested the contrary - that the buried body is the major contributor to the grave response. It should be noted, however, that particular study was done in a sandy (entisol) environment where the dielectric contrast between the target body and the sand might have been higher than is the case at FABF.

\section{December 2014}

Here, the post-mortem intervals of graves 1-20 are all in the range 55-64 days, except for the two scavenged graves, which were backfilled 31 days earlier. The individual grave responses are still evident on the corresponding depth slice (Figure 5), but the anomalies appear to be less sharp than before. As one might have expected, the relatively fresh graves (21-24), which are only nine days old, do appear to manifest more prominently on the depth slice image than the other, older graves. This observation may indicate the earlier assertion that in the first few days after burial an intact thorax cavity may cause grave responses to be more pronounced than say after a week or two. It can, however, also be argued from these results that without a priori information it would not necessarily be possible to confidently discriminate between a grave that is approximately one week old and one that is two months old. It is also not possible to discriminate between the responses of undisturbed grave that are $\sim 2$ months old (e.g., graves 9-12) and those of graves that were excavated and backfilled more recently (e.g., graves 17-20); this adds further weight to the inference that in this particular environment the disturbed burial zone is the major contributor to the total grave response.

\section{January 2015}

The depth slice in Figure 6 reveals that the contrast between grave anomalies and background and hence the detectability of graves has deteriorated significantly between early December 2014 and mid-January 2015. 
Individual grave anomalies can also still easily be identified on the $2 \mathrm{D}$ section (Figure 2), but the data contains a lot more clutter than in the previous two surveys. The relatively sudden decrease in contrast and detectability was attributed to the heavy seasonal rains that occurred between early December 2014 and January 2015 (Figure 7), but it was pointed out that this would need to be investigated further (van Schoor et al., 2015). Subsequently, site-specific confirmation of the increasing soil moisture content due to increasing rainfall was determined and is provided in the form of semi-quantitative soil water content (SWC) estimates derived from the GPR data. A method that uses the average radar velocity in the near surface to derive the apparent soil permittivity, and subsequently a soil water content estimate, was used. The method, which is described in Huisman et al. (2003), involves deriving average soil velocities from diffraction hyperbolae. More recently, an alternative method for estimating SWC from early-time GPR data has been described (e.g., Di Matteo et al., 2013; Ferrara et al., 2013). This method focuses on the envelope or instantaneous phase of individual radar traces, which contains diagnostic information about the soil dielectric properties; the derived average envelope amplitude (AEA) parameter has been shown to correlate well with changes in near-surface soil permittivity. Van Dam et al. (2016) pointed out that the early-time method is useful in cases of electrically conductive soils where other GPR-based methods may fail due to limited penetration. However, at the FABF site, where there multiple observable diffraction hyperbolae are present down to the intended target depth of approximately $60-70 \mathrm{~cm}$, the velocity-based estimation method is expected to provide a better estimate of the bulk SWC of the combined soil layers overlying the average target depth.

The interactive velocity adaptation tool in REFLEXW was used to determine the radar velocities and the following equation was used to derive the permittivity:

$$
v=\frac{c}{\sqrt{\varepsilon^{\prime}}}
$$

where $v$ is the radar velocity and $\varepsilon^{\prime}$ is the real part of the relative dielectric permittivity.

The relationship used to derive the $\operatorname{SWC}(\theta)$ from the apparent soil permittivity is based on an empirically determined equation (Topp et al., 1980):

$$
\theta=-5.3 \times 10^{-2}+2.92 \times 10^{-2} \varepsilon-5.5 \times 10^{-4} \varepsilon^{2}+4.3 \times 10^{-6} \varepsilon^{3}
$$

The transient behaviour of the estimated SWC for the FABF site over the GPR study period is plotted in Figure 7. Note that the 09 January 2015 and 31 March 2015 GPR surveys were associated with the highest estimated 

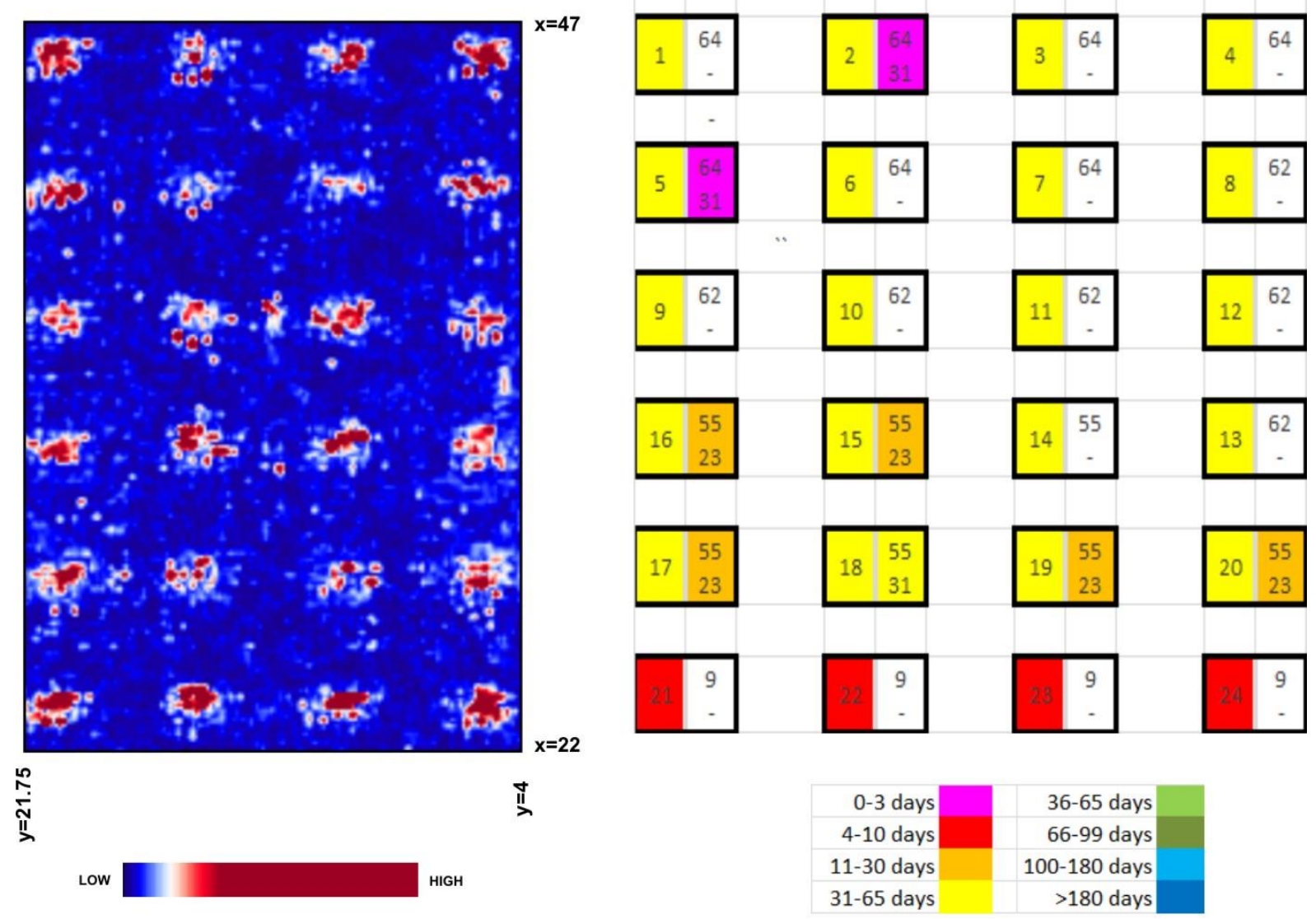

FIGURE 5: Depth slice and grave status information for the 03 December 2014 survey. 


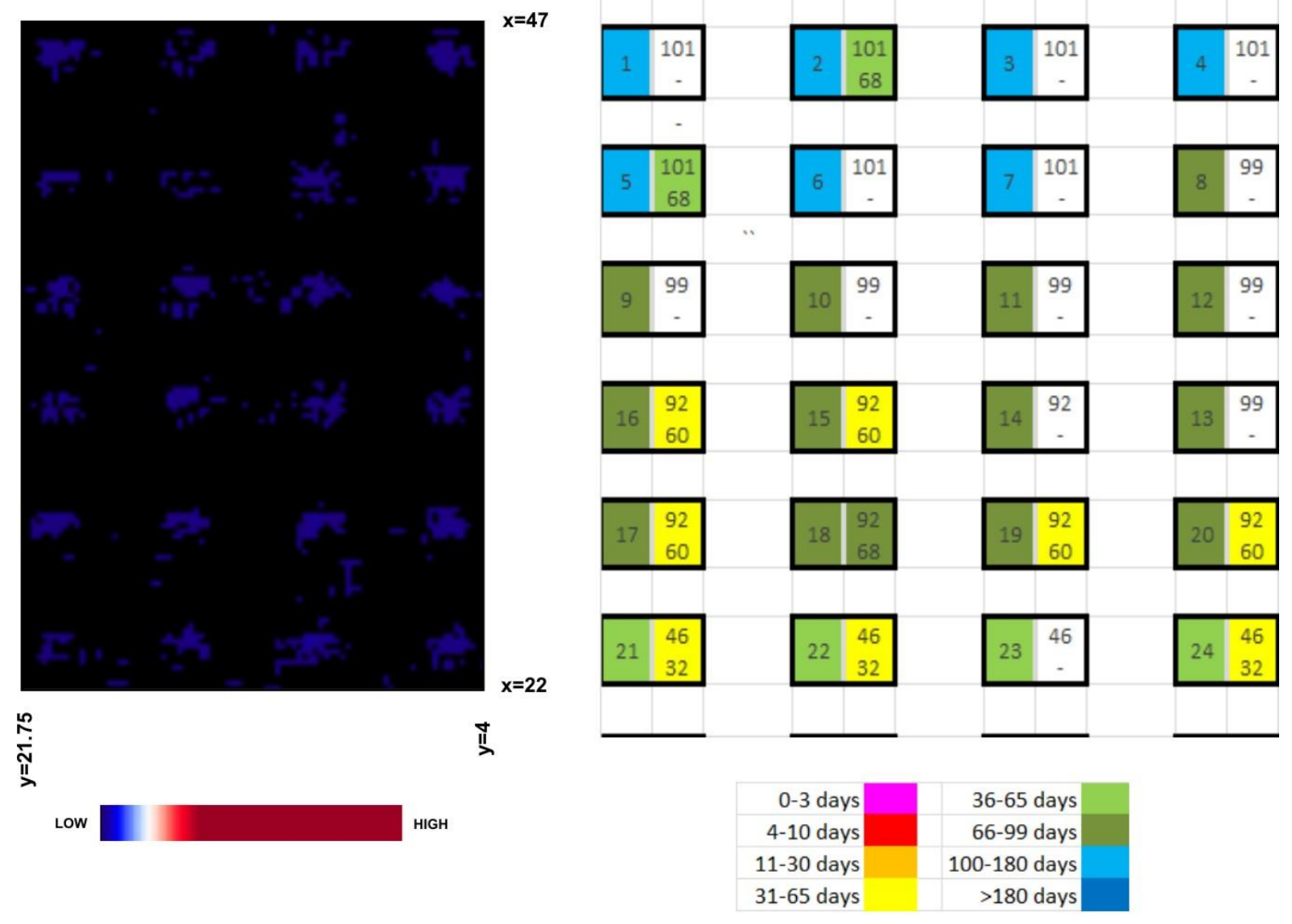

FIGURE 6: Depth slice and grave status information for the 09 January 2015 survey. 


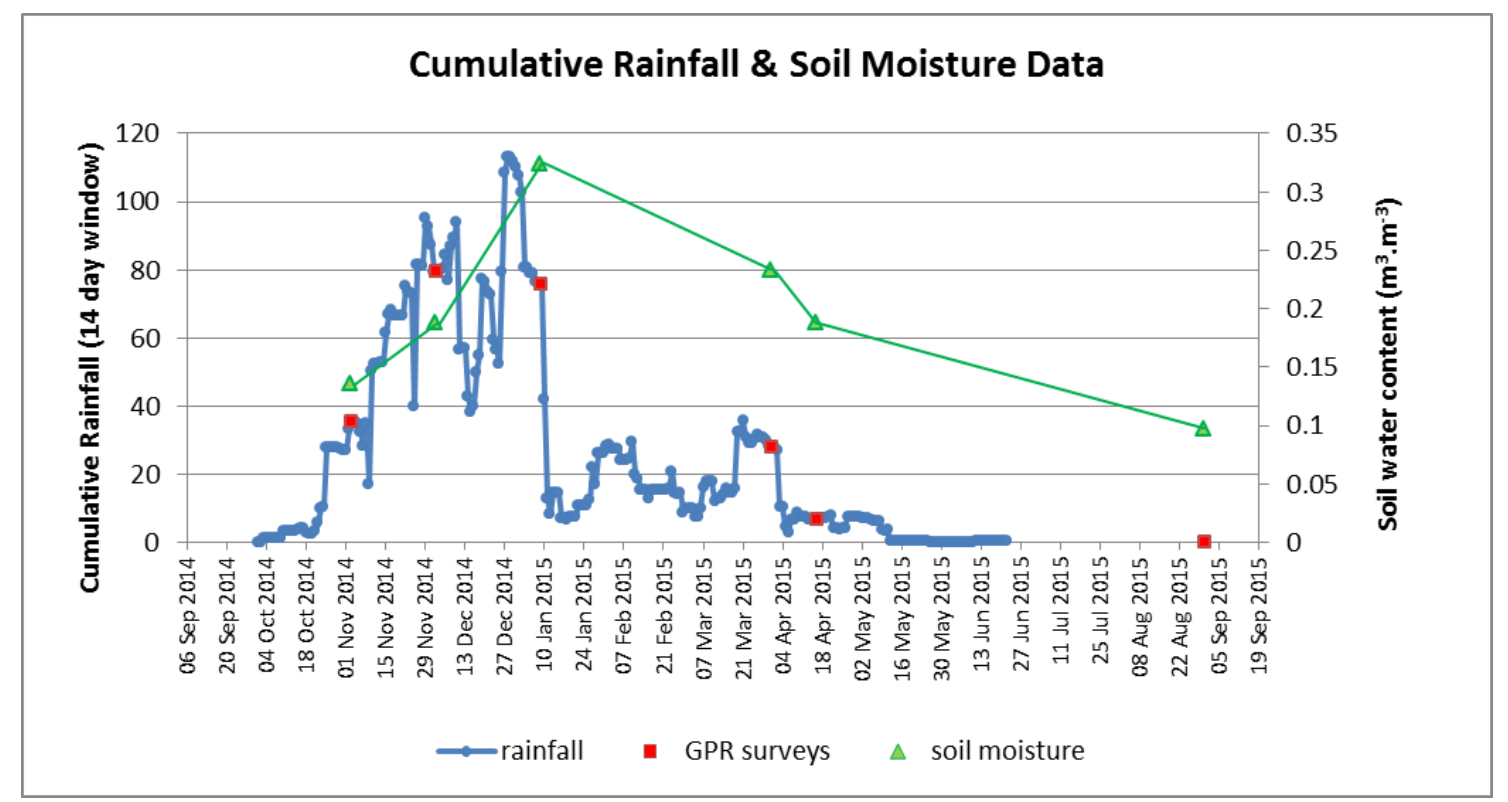

FIGURE 7: Cumulative rainfall (for a running 2-week window) and site-specific soil moisture data (derived from GPR velocity information). 
SWC levels of $0.32 \mathrm{~m}^{3} \cdot \mathrm{m}^{-3}$ and $0.23 \mathrm{~m}^{3} \cdot \mathrm{m}^{-3}$, respectively. These SWC levels compare well with published field capacity values for clay-rich loamy soils (IAEA, 2008).

The rapid increase in soil moisture content, coupled with the relative poor drainage of the loamy soil is thought to have resulted in the bulk conductivity of the ground increasing and the contrast between the target graves and their surroundings decreasing.

\section{March 2015}

Between January and March 2015 the observed anomaly contrast and grave detectability continued to decrease rapidly and this is evident in both 2D and 3D data (Figures 2 and 8). Even the anomalies associated with the relatively fresh graves 27-32 (post-mortem interval of 11-12 days) are not as prominent and easy to detect as in the first two 3D surveys. An interesting consequence is that some of the (hyperbolic) grave anomalies on the 2D section (Figure 2) appear easier to identify than the corresponding anomalies on the selected depth slice (Figure 8). This case study highlights an important pitfall of 3D GPR forensic surveys: one cannot always rely solely on depth slice information when searching for subtle anomalies such as those anticipated for clandestine graves. This is especially so in cases of complicating environmental variables such as heavy and frequent rainfall. In such cases it is advisable to analyse depth slices in conjunction with corresponding 2D radargrams as subtle anomalies may be easier to identify on the latter.

\section{April 2015}

In the two weeks subsequent to the 30 March 2015 survey, the upper portion of the soil profile dried out appreciably and the target-host contrast increased again as seen in the depth slice for the 16 April 2015 survey shown in Figure 9. The southwestern corner of the survey area however is still characterised by a relatively high degree of clutter and unwanted noise; this anomalous zone correlated with an area where drainage / drying out 


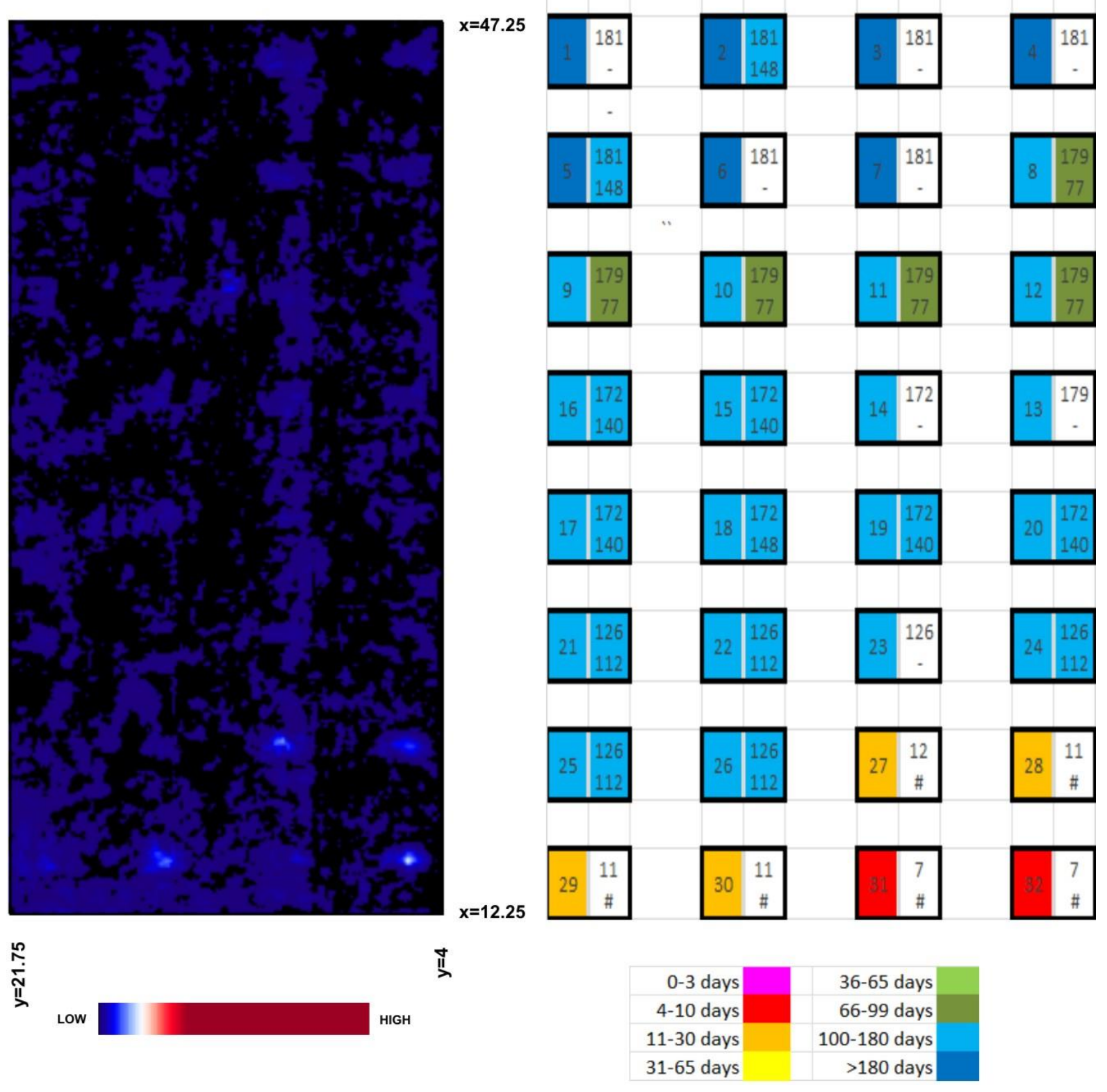

FIGURE 8: Depth slice and grave status information for the 31 March 2015 survey. 


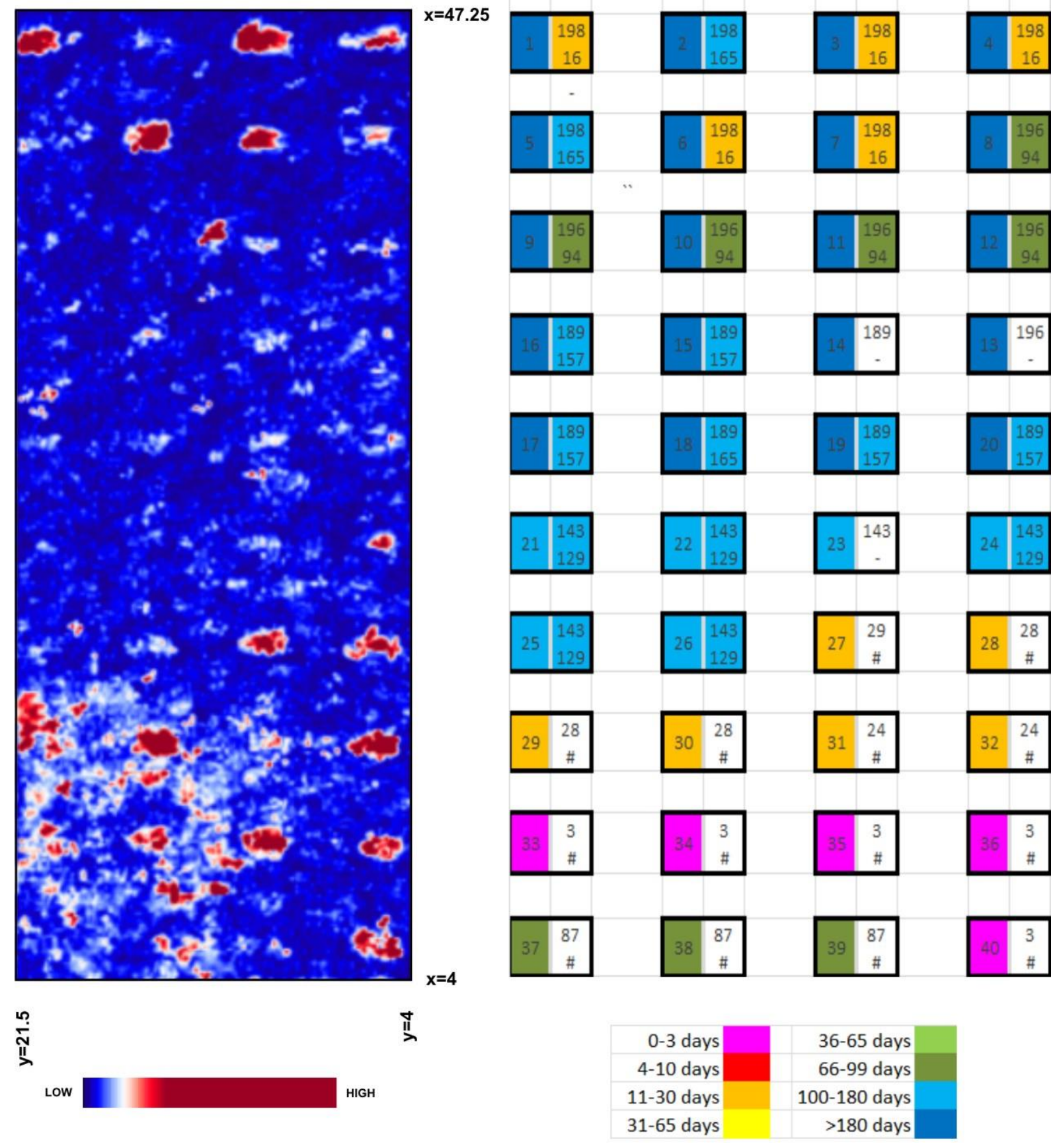

FIGURE 9: Depth slice and grave status information for the 16 April 2015 survey. 


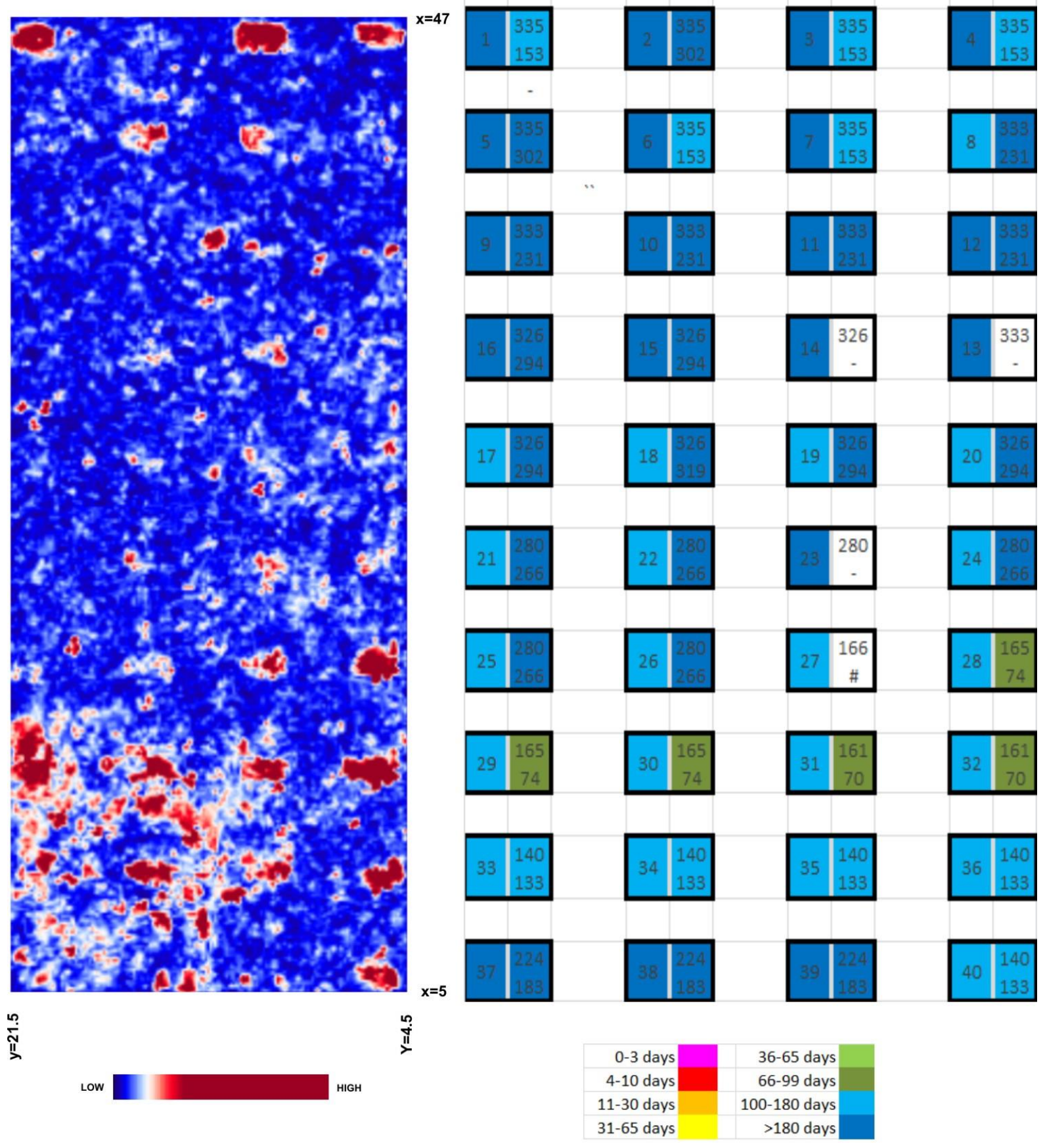

FIGURE 10: Depth slice and grave status information for the 31 August 2015. 
appeared to occur much slower than over the rest of the grid. Note that the graves associated with the most recent soil disturbances manifest most prominently on the displayed depth slice; for example, the three-day-old graves 33-36, 40 and $\sim$ one-month old graves 27-32; also, the recently excavated graves 1, 3,4,6 and 7. This is further confirmation that for this specific environment the clandestine grave anomaly is primarily the response of the disturbed soil zone.

\section{August 2015}

A final 3D survey was completed on 31 August 2015, towards the end of the dry winter months. The results are similar to that of the earlier April survey; however, an overall deterioration in image quality is apparent (Figure 10). This gradual deterioration could be attributed to the effect of the wet-dry cycle and continued settling of the disturbed soil zones. There are nevertheless indications that some of the observed anomaly contrasts have increased slightly from April to August 2015 (for example, graves 3 and 7 in the 2D profile seen in Figure 2 and graves 28 and 32 in the respective depth slices), which can be attributed to the decrease in soil moisture content between April and August 2015 (Figure 7). It is however clear that only those graves that were last disturbed after or towards the end of the rainy season are still reasonably detectable.

\section{CONCLUSIONS}

This controlled study confirmed that 3D GPR is a valuable tool when conducting forensic grave searches. It was, however, also shown that environmental variables such as soil type and rainfall can have a significant impact on the detectability of clandestine burials and that in such cases a combined 3D and 2D GPR approach is strongly advocated.

The site-specific combination of soil type (A Hutton form clay-rich loam, characterised by poor drainage) and clandestine burials (absence of coffin or artefacts that could enhance the target responses) resulted in the detectability of clandestine graves to be highly dependent on the season and to a lesser extent on post-mortem 
interval. Soaking seasonal rains contributed to an increase in soil moisture content and ground conductivity and an associated increase in radar signal attenuation, noisier data, more rapid settling of the disturbed burial zone and consequently lower observed anomaly contrasts. Although a return to lower soil water content levels in the dry season resulted in an overall increase in grave anomaly contrast, this does not really help to increase the detectability of graves that went through a complete wet-dry cycle and associated settling of the disturbed soil zones. Generally, graves could remain detectable up to six month after the burial provided that the post-mortem interval is not characterised by excessive rainfall. Even normal seasonal rains could render clandestine graves to become challenging to detect.

It was demonstrated that the decrease in GPR performance described above was more pertinent in the cased of the 3D depth slice analyses. This highlights a key point of this study; that is, when conducting 3D GPR surveys, one should not only rely on depth slice information when searching for graves. The deterioration of grave responses over time due to the previously described variables may result in very subtle anomalies on individual depth slices; it is good practice to consider a series of successive slices in conjunction with corresponding 2D radargrams when trying to identify possible grave anomalies. It was shown that, in some cases, the characteristic hyperbolic response patterns associated with graves can still be identified on radargrams, but these anomalies do not necessarily manifest as easily identifiable anomalies on the 3D depth slices.

Finally, several follow-up forensic research possibilities can be suggested: for example, a study to quantify the detectability of graves after a second summer rainfall season; that is, up to two years after burial. It would also be useful to know whether the addition of clothes, plastic bags or other body coverings would perhaps increase the detectability window of opportunity. 


\section{REFERENCES}

Annan, A.P. 1999. Practical processing of GPR data. Proceedings of the second government workshop on ground penetrating radar. Sensors \& Software Inc.

Barone, P.M., Swanger, K.J., Stanley-Price, N. and Thursfield, A. 2016. Finding graves in a cemetery: Preliminary forensic GPR investigations in the Non-Catholic Cemetery in Rome (Italy). Measurement 80, 5357.

Doolittle, J.A. and Bellantoni, N.F. 2010. The search for graves with ground-penetrating radar in Connecticut. Journal of Archaeological Science 37, 941-949.

Di Matteo, A., Pettinelli, E. and Slob, E. 2013. Early-Time GPR Signal Attributes to Estimate Soil Dielectric Permittivity: A Theoretical Study. IEEE Transactions on Geoscience and Remote Sensing 51(3), 1643-1654

Ferrara, C., Barone, P.M., Steelman, C.M., Pettinelli, E. and Endres, A.L. 2013. Monitoring Shallow Soil Water Content Under Natural Field Conditions Using the Early-Time GPR Signal Technique. Vadose Zone Journal 12(4), 1-9. DOI: $10.2136 / v z j 2012.0202$.

Fiedler, S., Illich, B., Berger, J. and Graw, M. 2009. The effectiveness of ground-penetrating radar surveys in the location of unmarked burial sites in modern cemeteries. Journal of Applied Geophysics 68, 380-385.

Hansen, J.D., Pringle, J.K. and Goodwin, J. 2014. GPR and bulk ground resistivity surveys in graveyards: Locating unmarked burials in contrasting soil types. Forensic Science International 237, e14-e29.

Huisman, J.A., Hubbard, S.S., Redman, J.D. and Annan, A.P. 2003. Measuring Soil Water Content with Ground Penetrating Radar: A Review. Vadose Zone Journal 2, 476-491.

Molina, C. M., Pringle, J.K., Saumett, M. and Hernández, O. 2015. Preliminary results of sequential monitoring of simulated clandestine graves in Colombia, South America, using ground penetrating radar and botany. Forensic Science International 248, 61-70.

Novo, A., Lorenzo, H., Rial, F.I. and Solla, M. 2011. 3D GPR in forensics: Finding a clandestine grave in a mountainous environment. Forensic Science International 204, 134-138. 
Pringle, J. K., Jervis, J., Cassella, J.P. and Cassidy, N.J. 2008. Time-Lapse Geophysical Investigations over a Simulated Urban Clandestine Grave. Journal of Forensic Science 53, 1405-1416.

Pringle, J.K., Ruffell, A., Jervis, J.R., Donnelly, L. McKinley, J., Hansen, J., Morgan, R., Pirrie, D. and Harrison, M. 2012. The use of geoscience methods for terrestrial forensic searches. Earth-Science Reviews 114, $108-123$

Salsarola, D., Poppa, P., Amadasi, A., Mazzarelli, D., Gibelli, D., Zanotti, E., Porta, D., and Cattaneo, C. 2015. The utility of ground-penetrating radar and its time-dependence in the discovery of clandestine burials. Forensic Science International 253, 119-124

Schultz, J. J. 2008. Sequential Monitoring of Burials Containing Small Pig Cadavers Using Ground Penetrating Radar. Journal of Forensic Science 53, 279-287.

Schultz, J. J., and Martin, M.M. 2012. Monitoring controlled graves representing common burial scenarios with ground penetrating radar. Journal of Applied Geophysics 83, 74-89.

Schultz, J.J. 2012. The Application of Ground-Penetrating Radar for Forensic Grave Detection. In: D. Dirkmaat (ed.), A companion to forensic anthropology. John Wiley \& Sons.

Topp, G.C., Davis, J.L. and Annan, A.P. 1980. Electromagnetic determination of soil water content: Measurements in coaxial transmission lines. Water Resources Research 16, 574-582.

IAEA, 2008. Field Estimation of Soil Water Content: A Practical Guide to Methods, Instrumentation and Sensor Technology (PDF), Vienna, Austria: International Atomic Energy Agency, 2008, p. 131, ISSN 1018-5518, IAEA-TCS-30

Van Dam, R.L., Algeo, J. and Slater, L. 2016. The GPR early-time method to measure water content of clay soils. VII Simpósio Brasileiro de Geofísica, 25-27 October 2016. Sociedade Brasileira de Geofísica.

Van Schoor, M., Nienaber, W.C. and Marais-Werner, A. 2015. A controlled monitoring study of simulated clandestine graves using 3D ground penetrating radar. Near Surface Geoscience 2015 - 21st European Meeting of Environmental and Engineering Geophysics. ISBN: 978-1-5108-1412-7 